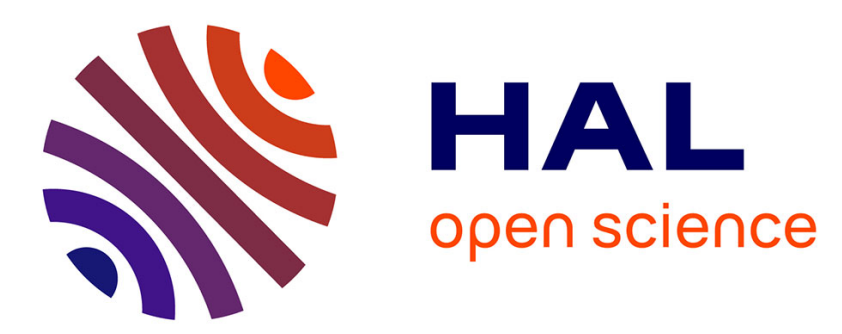

\title{
Microbial Pigments From Bacteria, Yeasts, Fungi, and Microalgae for the Food and Feed Industries
}

Laurent Dufossé

\section{To cite this version:}

Laurent Dufossé. Microbial Pigments From Bacteria, Yeasts, Fungi, and Microalgae for the Food and Feed Industries: Chapter 4. Alexandru Grumezescu; Alina Maria Holban. Handbook of food bioengineering, VII, Elsevier, pp.113-132, 2017, Natural and Artificial Flavoring Agents and Food Dyes, 978-0-12-811518-3. 10.1016/B978-0-12-811518-3.00004-1 . hal-01615454

\section{HAL Id: hal-01615454 \\ https://hal.univ-reunion.fr/hal-01615454}

Submitted on 12 Oct 2017

HAL is a multi-disciplinary open access archive for the deposit and dissemination of scientific research documents, whether they are published or not. The documents may come from teaching and research institutions in France or abroad, or from public or private research centers.
L'archive ouverte pluridisciplinaire $\mathbf{H A L}$, est destinée au dépôt et à la diffusion de documents scientifiques de niveau recherche, publiés ou non, émanant des établissements d'enseignement et de recherche français ou étrangers, des laboratoires publics ou privés. 


\title{
Microbial Pigments From Bacteria, Yeasts, Fungi, and Microalgae for the Food and Feed Industries
}

\author{
Laurent Dufossé \\ University of Reunion Island, Saint-Denis, France
}

\section{Introduction}

Ingredients derived from microbial fermentation or extracted from algae are steadily gaining ground in the food, the feed, or other industries. Thickening or gelling agents (e.g., polysaccharides, such as xanthan, curdlan, gellan), flavor enhancers (yeast hydrolysate, monosodium glutamate), polyunsaturated fatty acids (PUFAs), flavor compounds (gammadecalactone, diacetyl, methyl-ketones), vitamins, essential amino acids, and acidulants (lactic acid, citric acid) are some examples illustrating this trend. Efforts have been made and continue to be done in order to reduce the production costs of pigments produced by algal ponds and microbial fermentation (Mannazzu et al., 2015) because synthetic pigments or those extracted from natural plant sources can often be produced more economically (Dufossé et al., 2005). The successful marketing of natural pigments, such as $\beta$-carotene, lutein, and astaxanthin derived from algae (i.e., nonconventional sources) (Jaswir et al., 2011) or extracted from flowering plants (conventional sources), both as food colorants and nutritional supplements (Zhou et al., 2015), reflects the presence and importance of niche markets in which consumers are willing to pay a premium for "natural healthy ingredients." Among other nonconventional sources, filamentous fungi are known to produce an extraordinary range of pigments that include several chemical classes, such as carotenoids, melanins, azaphilones, flavins, phenazines, quinones, and more specifically, monascins, violacein, and indigo (Dufossé, 2006). The success of any class of pigment produced by fermentation depends on its acceptance by the consumers, regulatory approval, and the capital investment required bringing the product onto the market. Twenty years ago, influential representatives from the food industry expressed doubts about the successful commercialization of algae-derived and fermented food-grade pigments due to the high investment required for open ponds, photobioreactors, and fermentation facilities, and the extensive and lengthy toxicity studies required by the regulatory authorities. Poor public 
perception of fungal-derived products for food use had also to be taken into account. Nowadays, some algal food-grade pigments obtained by fermentation are existing on the market worldwide. Among them, fungal Monascus pigments, Arpink Red (now Natural Red) produced by Penicillium oxalicum, microalgal phycocyanin from Arthrospira (Spirulina) platensis, riboflavin from the mold fungus Ashbya gossypii, lycopene and $\beta$-carotene from the tropical mold Blakeslea trispora (Chen et al., 2016), $\beta$-carotene from the microalgae Dunaliella salina, and astaxanthin from the bacterium Paracoccus carotinifaciens and microalgae Haematococcus pluvialis (Grassi et al., 2016), respectively. As an example, the production yield of $\beta$-carotene may be as high as $17 \mathrm{~g} / \mathrm{L}$ of the $B$. trispora culture medium (Dufossé et al., 2014).

Thus, the present chapter emphasizes the crucial role that microorganisms and microalgae are currently playing and are likely to continue to play in future as microbial cell factories for the production of food-grade pigments for the industry. This is due to the versatility in their pigment color and chemical profile (Fig. 4.1), amenability for easy large-scale cultivation, and a long history of production by well-investigated production strains (Fig. 4.2).

In this chapter, attention of both the academia and the food industry is drawn to some stimulating findings in the research of microbial and algal pigments considering various approaches from simple screening until molecular biology.

\section{Carotenoids}

\subsection{Lutein and Zeaxanthin}

Lutein, being a member of the carotenoid class, namely the xanthophylls subclass, is a yellow pigment occurring in higher plants and other photoautotrophic organisms like algae (Berman et al., 2014). Lutein is used as a feed additive to brighten the colors of bird feathers, and standardize the yellow of egg yolk and broilers (Silva et al., 2016). Lutein is also applied to add color to foods. Additionally, lutein, being an effective functional nutrient, may add benefits to human health regarding cardiovascular diseases, cancers, cognitive function, and age-related macular degeneration (AMD). The worldwide market for lutein is expected to grow to US $\$ 308$ million by 2018 (Lin et al., 2014). As marigold (Tagetes erecta L.) flowers must be harvested periodically, extraction of this conventional lutein source represents a seasonal and labor-intensive process. Therefore, several microalgae have been proposed as potential alternative sources of lutein (Lin et al., 2014), as they have high lutein content. Other advantages of lutein production from microalgae include the following:

1. Microalgae are a cheap and effective bioresource that can be used to produce value-added compounds, including fine chemicals, vitamins, carotenoids, and polysaccharides.

2. Growth rates of microalgae are about 5-10 times higher than of higher plants. 


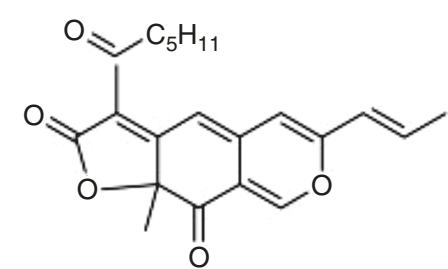

Rubropunctatine<smiles>C/C=C/C1=CC2=CC3=C(C(=O)CCC)C(=O)OC3(C)C(=O)C2=CN1</smiles>

Monascorubramine

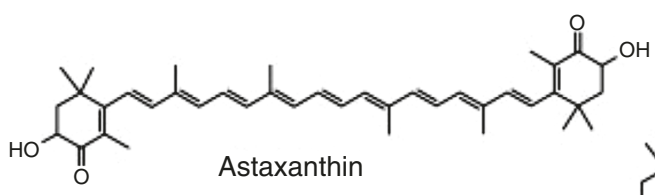

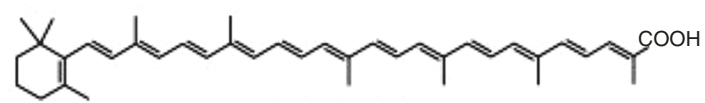

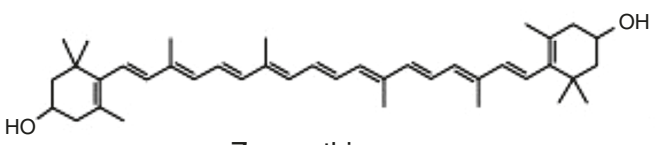

Torularhodin

Zeaxanthin

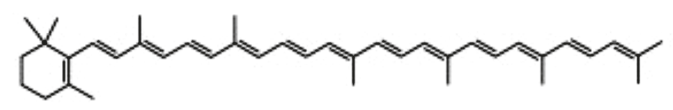

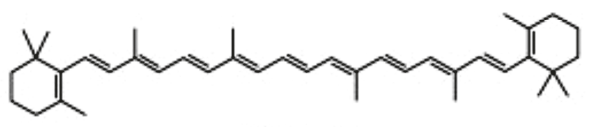

Torulene

$\beta$-Carotene

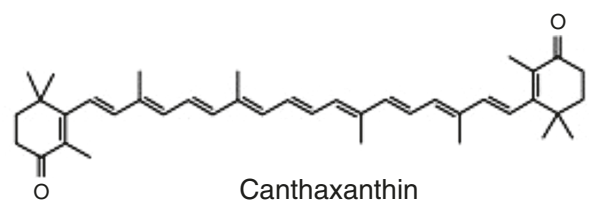

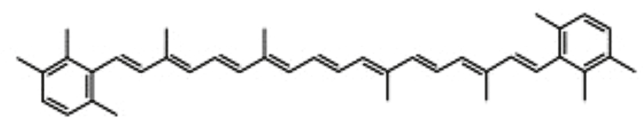

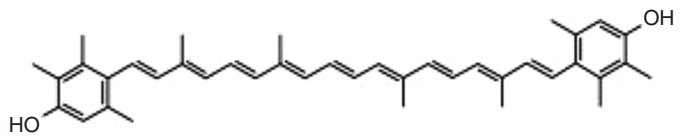

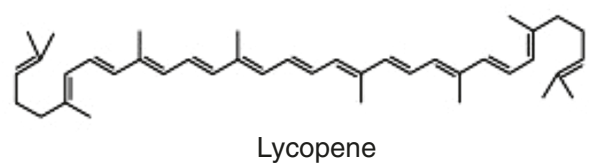
3,3'-Di-hydroxy-Isorenieratene<smiles>C=C(C)C=Cc1c(O)cc(CC)c2c1C(=O)c1cc(O)c(C(=O)O)cc1C2=O</smiles><smiles>Cc1cc2nc3c(=O)[nH]c(=O)nc-3n(CC(O)C(O)C(O)CO)c2cc1C</smiles>

Figure 4.1: Chemical Formulae of Some Microbial Food-Grade Pigments. 

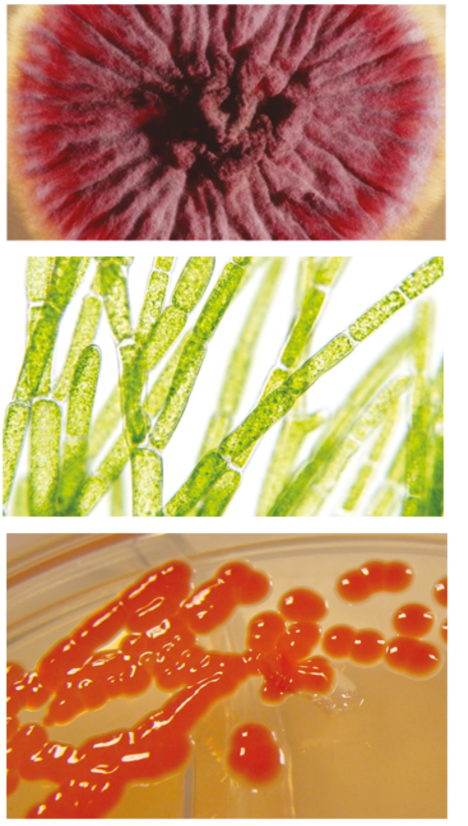

Screening for microorganisms producing pigments of interest without any coproduction of toxins

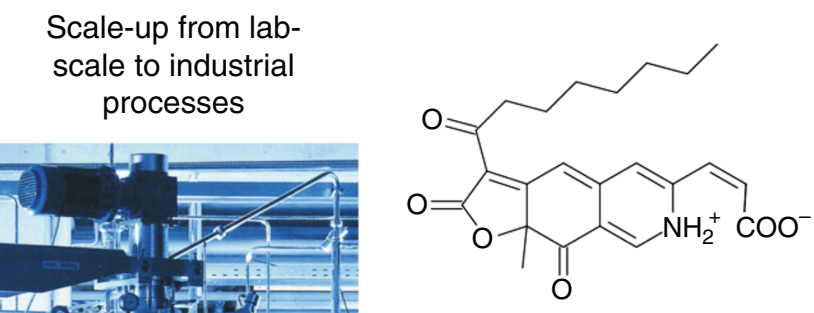

Monascus-like pigment produced by Talaromyces fungi<smiles>COc1c(O)c(O)c2c(c1O)C(=O)c1cc(C)cc(O)c1C2=O</smiles>

Hydroxy-anthraquinone from Dermocybe

Access to pigments already known in the food industry or to new compounds that need funds for regulatory approval

Figure 4.2: Using Microalgae, Fungi, Yeasts, and Bacteria as Cell Factories for the Production of Natural Food Pigments.

3. Microalgae, which can be cultivated in seawater or brackish water and on nonarable land, do not compete for resources with conventional agricultural crops.

4. Microalgal biomasses can be harvested all year round in many parts of the world (Lin et al., 2014).

The following lutein contents converted to $\mathrm{g} / \mathrm{kg}$ biomass have been reported for various microalgal species (Lin et al., 2014): Chlorella fusca (4.2-4.7), Chlorococcum citroforme (7.4), Coelastrum proboscideum (3.4-5.0), Muriella aurantiaca (2.6), Muriella decolor (0.5), Neospondiococcum gelatinosum (4.4), Tetracystis aplanosporum (5.9), Tetracystis intermedium (3.5), Tetracystis tetrasporum (4.4), Chlorella zofingiensis (2.4-2.8). Further, species yielding high lutein contents have been identified, such as Chlorella protothecoides and Calluna vulgaris, Scenedesmus obliquus, and other species, as well as Desmodesmus sp. A reasonable estimate for lutein yields in microalgal biomass is $5 \mathrm{~g} / \mathrm{kg}$, mostly in the free form, while in plants, lutein and zeaxanthin concentrations from marigold flowers amount to 15 and $2.5 \mathrm{~g} / \mathrm{kg}$ biomass, respectively, mostly in the ester form (Guedes et al., 2011; Lin et al., 2014). 
The second xanthophyll of interest, the yellow pigment known as zeaxanthin or 3,3'-dihydroxy$\beta$-carotene can be used, for example, as an additive to poultry feed to intensify the yellow color of the broiler and accentuate the color of the egg yolk. In addition to its application as a feed additive or food colorant, this xanthophyll is also suited for the prevention of AMD, for example, in nutraceuticals and as dietary supplements in the food industry.

In the mid-1960s, scientists at Hoffmann-La Roche isolated several marine bacteria that produced zeaxanthin. Flavobacterium sp. (ATCC 21588, classified under the accepted taxonomic standards of that time) when cultured in a nutrient medium containing glucose or sucrose, sulfur-containing amino-acids, such as methionine, cystine or cysteine, pyridoxine, and bivalent metal ions selected from the group consisting of $\mathrm{Fe}^{++}, \mathrm{Co}^{++}, \mathrm{Mo}^{++}$, or $\mathrm{Mn}^{++}$were able to produce up to $190 \mathrm{mg}$ of zeaxanthin per liter, with a specific concentration of $16 \mathrm{mg} / \mathrm{g}$ dried cellular mass (US Patent 5,827,652). Flavobacterium multivorum (ATCC 55238) is currently under investigation in many studies (Thawornwiriyanun et al., 2012).

According to taxonomic reclassification, the zeaxanthin-producing Flavobacterium has been grouped into the new genus Paracoccus, namely Paracoccus zeaxanthinifaciens. This may become an industrial product in some years, as for astaxanthin Panaferd-AX from $P$. carotinifaciens, which has been developed by JX Nippon Oil and Energy for imparting color to animal feed (US Patent 8,853,460 and US Patent application 20,130,012,594). A second strain was isolated in a mat from an atoll of French Polynesia (Raguenes et al., 2004). This strain is peculiar, as it also produces exopolysaccharides.

Another zeaxanthin-producing bacterium, S. multivorum, was recently shown to utilize the deoxyxylulose-5-phosphate (DXP) pathway. For overproduction of zeaxanthin in large quantities, a strain was constructed (US Patent 5,308,759). Since more bacteria are recently being examined for the two different pathways of IPP biosynthesis (Calegari-Santos et al., 2016; Lange et al., 2000), the distribution of the mevalonate and DXP pathways will be better understood. Furthermore, identification of genes involved in IPP biosynthesis lends itself to metabolic engineering of microorganisms having improved productivity of commercially important isoprenoid compounds, including carotenoids.

\subsection{Aryl Carotenoids (Orange Colors and Highly Active Antioxidants) Are Specific to Some Microorganisms}

Aryl carotenoids, such as isorenieratene and its hydroxyl derivatives (Fig. 4.3) are produced by a very small number of microorganisms. Some are anaerobic and photosynthetic (Chlorobiaceae, Chromatiaceae). Being easier to cultivate, nonphotosynthetic bacteria containing aryl carotenoids, such as Brevibacterium linens (Fig. 4.4), Streptomyces mediolani, and Mycobacterium aurum are of high interest. All mentioned examples belong to the Actinomycetales, an order of Actinobacteria (Dufossé and de Echanove, 2005). 


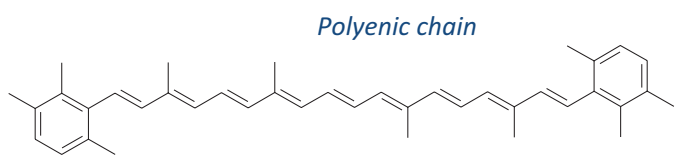

Isorenieratene

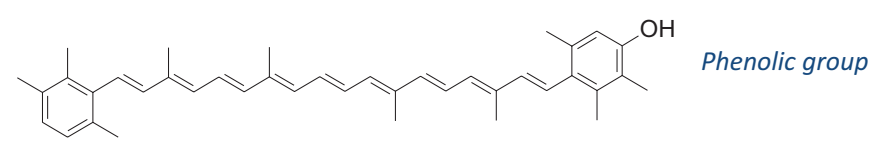

3-Hydroxy-isorenieratene<smiles>CC(/C=C/C=C(C)/C=C/C=C(C)/C=C/c1c(C)cc(O)c(C)c1C)=C\C=C\C=C(C)\C=C\c1c(C)cc(O)c(C)c1C</smiles>

3,3'-Di-hydroxy-isorenieratene

Figure 4.3: Aryl Carotenoids Described in Brevibacterium linens.

The main interest in $B$. linens consists in that this bacterium is part of the microbiota of smear-ripened cheeses. This may facilitate overcoming regulatory obstacles of using the carotenoids derived from its bacterial biomass as food ingredients. However, up to now, levels of production in liquid media are limited to $0.50-1.0 \mathrm{mg} / \mathrm{L}$, a concentration of aryl carotenoids being too low to envisage their industrial production (Guyomarc'h et al., 2000).

When comparing the antioxidant potential of carotenoids including astaxanthin, $\beta$ cryptoxanthin, zeaxanthin, lycopene, lutein, and the microbial 3,3'-dihydroxyisorenieratene

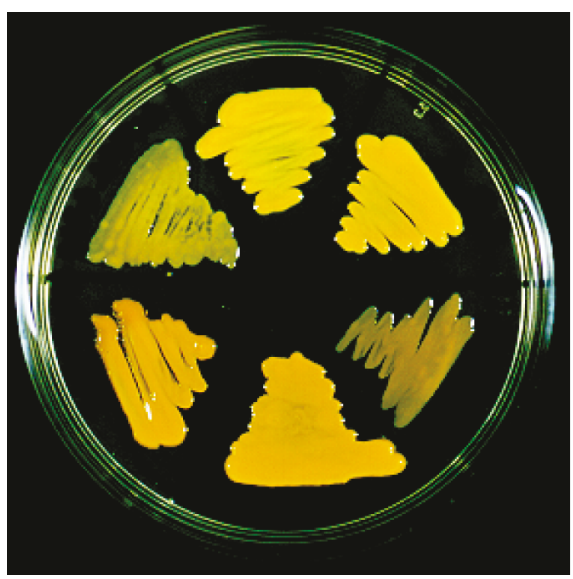

(A)

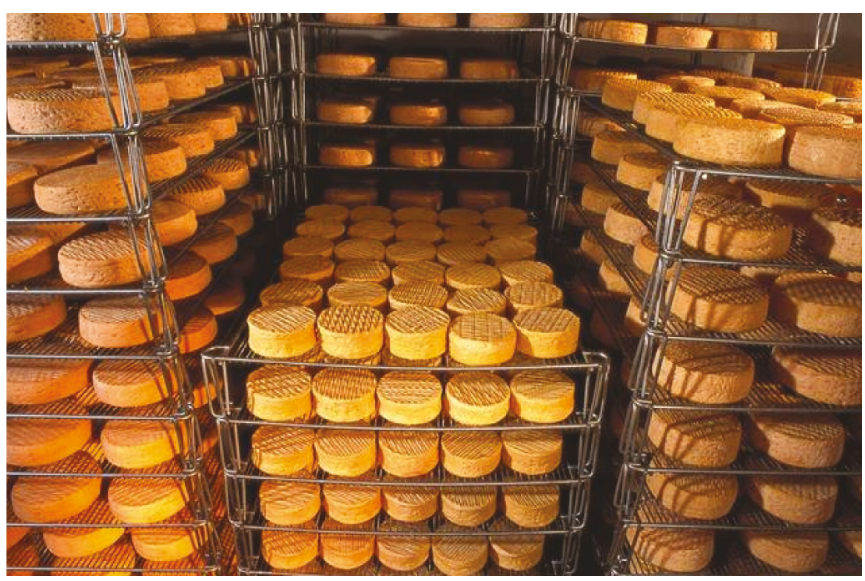

(B)

Figure 4.4: Production of aryl carotenoids by Brevibacterium linens on a Petri dish $(A)$ and on Livarot cheeses (B). 
(DHIR), the latter proved to be superior, ranking on "top of the list" regarding the radical scavenging and singlet oxygen quenching activity (Wagener et al., 2012). The experimental data obtained based on various antioxidant assays suggest that DHIR acts as a bifunctional radical scavenger owing to its polyenic and phenolic substructures (Martin et al., 2009).

Aryl carotenoids have been studied for some decades, starting with the first patent in 1971 (US Patent 3,598,702). Using B. linens as a food-grade bacterium for microbial production, the concentration of aryl carotenoids in the culture medium does not suffice to allow their commercialization at a competitive price. Consequently, for the short- and midterm, chemical synthesis may be an alternative. The German company BASF as well as academic researchers have now developed novel syntheses (Valla et al., 2003); however, aryl carotenoids, such as isorenieratene or DHIR are not yet available for large-scale applications. Genetical modifications of producing organisms could also be an alternative to obtain affordable polyenic-phenolic carotenoids (US Patent 7,186,523), which proved superior antioxidant activity, thus being of interest as bioactive food ingredients (patent application WO 2008009675).

\section{3 $C_{50}$ Carotenoids (Sarcinaxanthin, Decaprenoxanthin), Not Being Produced by Plants in Nature}

In nature, $\mathrm{C}_{50}$ carotenoids are exclusively biosynthesized by bacteria belonging to the Actinomycetales. Until now, only three different $\mathrm{C}_{50}$ carotenoid biosynthetic pathways have been described: (1) the $\beta$-cyclic $\mathrm{C}_{50}$ carotenoid C.p. 450 pathway in Dietzia sp. CQ4-C.p. letters are used as this carotenoid was first isolated in Corynebacterium poinsettiae; (2) the $\gamma$-cyclic $\mathrm{C}_{50}$ carotenoid sarcinaxanthin pathway in Micrococcus luteus NCTC 2665; and (3) the $\varepsilon$-cyclic $\mathrm{C}_{50}$ carotenoid decaprenoxanthin pathway in Corynebacterium glutamicum. More than $95 \%$ of all natural carotenoids originate from the symmetric $\mathrm{C}_{40}$ phytoene backbone, and only a small number of $\mathrm{C}_{30}$ and even fewer $\mathrm{C}_{50}$ carotenoids have been discovered in nature. The to-date known $\mathrm{C}_{50}$ carotenoids have multiple conjugated double bonds, at least containing one hydroxyl group; both of these features contribute to their strong antioxidant properties. Therefore, these carotenoids, which are only produced by microorganisms, may be suitable for food coloring as well as for nutraceutical and pharmaceutical applications (Heider et al., 2014).

\subsection{Directed Evolution and Molecular Breeding Techniques for the Production of Novel Carotenoids Exerting Improved Color Strength/Stability/Antioxidant Properties}

In the field of pigment research, the work on carotenoids is most advanced, and cutting-edge techniques have been employed to increase the level of production and to produce novel new carotenoids with improved properties (Castelblanco-Matiz et al., 2015; Chang et al., 2015;

Chi et al., 2015). 
As an example, directed evolution involves the use of rapid molecular manipulations to mutate the target DNA fragment, followed by a selection or screening process to isolate desirable mutants. In this manner, several carotenogenic enzymes have been improved or optimized for a specific condition using various directed evolution protocols. Directed evolution has been applied to geranylgeranyl diphosphate GGPP synthase from Archaeoglobus fulgidus being the rate-controlling enzyme to enhance the production of carotenoids in metabolically engineered Escherichia coli. The library of mutated genes that has been created using these tools was transformed into an E. coli strain containing the reconstructed isoprenoid pathway (Jin et al., 2015), and screened for color intensity to optimize the conversion of glucose into astaxanthin or lycopene. In summary, from more than 10,000 colonies, 8 mutants were obtained. The production of lycopene was almost doubled. In addition to the increased production of carotenoids, the directed evolution approach allowed the identification of hot regions that are important for either protein expression or specific activity (Schmidt-Dannert et al., 2000).

A second example refers to the membrane-associated carotenoid synthase that appears to be the major point of control over product diversity. The carotenoid synthase was engineered to accept longer diphosphate substrates and produced synthase variants being able to synthesize previously unknown $\mathrm{C}_{45}$ and $\mathrm{C}_{50}$ carotenoid backbones from the appropriate $\mathrm{C}_{20}$ and $\mathrm{C}_{25}$ isoprenyl diphosphate precursors. In a previous work, a $\mathrm{C}_{35}$ carotenoid backbone was also biosynthesized, and various downstream enzymes (desaturases and cyclases) from the $\mathrm{C}_{30}$ and $\mathrm{C}_{40}$ carotenoid pathways were functional on this nonnatural substrate, which led to the production of a series of novel carotenoids. Thus, it appears that once a carotenoid backbone structure is created, downstream enzymes, either natural or engineered, can accept the new substrate, and whole series of novel carotenoids can be produced. With the action of carotenoid-modifying enzymes, including desaturases, cyclases, hydroxylases, and cleaving enzymes, on these new backbones, it should be possible to double or even triple the diversity of the carotenoid class comprising about 750 structures up to now.

A different approach to expand the recombinant production of known carotenoids and to synthesize completely novel structures is to engineer novel pathways by combining available biosynthetic genes and evolving new enzyme functions through random mutagenesis, recombination (DNA-shuffling), and selection (Wang et al., 2007). Prerequisites for this approach are that carotenogenic Crt enzymes from different species can function cooperatively in a heterologous host and display enough promiscuity regarding the structure of their substrates (Dufossé, 2009). With a few exceptions, such as, for example, zeaxanthin $\mathrm{C}(5,6)$ epoxidase, almost all cloned carotenoid biosynthetic genes are functionally expressed in E. coli. The success of functional color expression in transgenic E. coli for the cloning of a number of carotenoid biosynthesizing genes demonstrates that enzymes from phylogenetically distant species can assemble into a functional membrane-bound multienzyme complex at which carotenoid biosynthesis takes place. Both phytoene desaturase 
(crtI) and lycopene cyclase (crtY) genes have been targeted for in vitro evolution to achieve synthesis of novel carotenoids in E. coli (Song et al., 2013). A variant enzyme, a desaturase chimera, efficiently catalyzed the extended desaturation of the linear $\mathrm{C}_{40}$ carotenoid pathway, introducing six rather than four double bonds into phytoene, thus enabling the production of the fully conjugated carotenoid, 3,4,3',4'-tetradehydrolycopene (Song et al., 2013).

A related strategy bypasses the shuffling step. Instead, carotenogenic genes from different bacteria are combined employing unique pathways that maintain altered product specificities in a simple $E$. coli host expressing the biosynthetic machinery for phytoene production. In conjunction with the four-step phytoene desaturase that yields lycopene, a five-step desaturase was used to produce 3,5-didehydrolycopene (Zhang et al., 2012). Further diversification of the $\mathrm{C}_{40}$ skeleton using a 1,2-hydratase and a C-3,4 desaturase yielded a range of carotenoids, including acyclic hydroxyl-containing products (1-OH-3,4,3', $4^{\prime}$ tetrahydrolycopene; $1,1^{\prime}$-dihydroxy-3,4-didehydrolycopene; $1^{\prime}, 3$-dihydroxy- $\gamma$-carotene) with significant antioxidant activity.

Recent achievements in metabolic engineering of E. coli (Kim et al., 2016; Li et al., 2015; Takemura et al., 2015) and yeast strains resulted in a significant increase in the productivity of isoprenoid compounds, such as carotenoids, by increasing the metabolic flux toward the isoprenoid precursors. However, decades after the beginning of research in this field (i.e., carotenogenic gene cluster from the bacteria Erwinia herbicola described in 1991), neither industry nor consumers did observe a surge or even the appearance of "engineered" carotenoids on the market, thus being a quite disappointing situation after so many millions euros invested.

\section{Azaphilones}

\subsection{Toward Mycotoxin-Free Monascus Red}

Monascus has been used to produce natural colorants and food supplements for more than 1000 years in Asia, and approximately more than 1 billion Asian people consume Monascus-fermented products with their daily diet. The first known source reporting the use of these red colorants was a recipe for the preparation of red pot-roast lamb, in which meat was simmered with hong qu (red rice koji, made with Monascus purpureus), as handed down in the Qing Yilu in AD 965. Monascus species are known to produce six major azaphilone pigments, namely the yellow monascin and ankaflavin, the orange monascorubrin and rubropunctatin, and the red monascorubramine and rubropunctamine. To date, more than 50 different chemical structures have been identified (Yang et al., 2015) as azaphilones easily combine with nitrogen containing compounds. Using next-generation sequencing and optical mapping approaches, a 24.1-Mb complete genome of a $M$. purpureus YY-1 industrial strain has been described for the first time and this will allow huge improvements in the process in the coming years (Yang et al., 2015). It consists of 
eight chromosomes and 7491 genes. M. purpureus should belong to the Aspergillaceae, mainly comprising the genera Monascus, Penicillium, and Aspergillus. Phylogenetic analysis at the genome level provides the first comprehensive prediction of the biosynthetic pathway for Monascus pigments. Comparative genomic analyses demonstrated that the genome of $M$. purpureus is $13.6 \%-40 \%$ smaller than that of closely related filamentous fungi and has undergone significant gene losses, most of which likely occurred during its specialized adaptation to starch-based foods. Some polyketide synthases (PKS) are expressed at high levels under high pigment yielding conditions. The citrinin PKS C6.123 has also been found in the genome (Yang et al., 2015), paving the way for research aiming at nonmycotoxin-producing strains, if suppression of the citrinin gene does not change the ability of the strain to produce pigments, which seems to be feasible, as described by Fu et al. (2007). The latter group has shown that monascorubrin and citrinin are synthesized by two separate pathways because when the PKS gene responsible for synthesis of citrinin was disrupted, red pigment production from the fungus was not affected. Comparative transcriptome analysis revealed that carbon starvation stress, resulting from the use of relatively low-quality carbon sources, contributed to the high yield of pigments by suppressing central carbon metabolism and augmenting the acetyl-CoA pool. As for other pigments produced by biotechnology, the problem is to have enough carbon oriented in the correct pathway, that is, the pigment pathway.

Woo et al. (2014) investigated another filamentous fungus, Penicillium marneffei, for production of azaphilones exhibiting black, yellow, and red hues. The polyketide gene cluster and biosynthetic pathway were reported for monascorubrin in this red pigment-producing, thermal dimorphic fungus, taking advantage of available genome sequence and faster growth rate compared to Monascus species (Woo et al., 2014). The red pigment of P. marneffei has been shown to consist of a mixture of more than 16 chemical compounds, which are amino acid conjugates of monascorubrin and rubropunctatin, as amino acids can be conjugated under specific conditions without enzymatic catalysis, that is, by Schiff base formation (Fig. 4.5) (Woo et al., 2014).

The aforementioned polyketide gene cluster and pathway has been shown to be also responsible for the biosynthesis of ankaflavin and citrinin, the latter being a mycotoxin exerting nephrotoxic activity in mammals (Kumar et al., 2014). Twenty-three putative PKS genes and two putative PKS-nonribosomal peptide synthase hybrid genes were identified in the P. marneffei genome (Woo et al., 2014). Woo et al. (2014) systematically knocked out all 25 PKS genes of P. marneffei. They also knocked out genes located up- and downstream of the PKS gene responsible for red pigment production and characterized the pathway for biosynthesis of the red pigment. However, it is still questionable whether it will be possible to produce mevinolin/lovastatin-free (a cholesterol-lowering drug that is undesired in normal foods) and citrinin-free red pigments from P. marneffei, as the latter, a mycotoxin, appears to be an early by-product of the biosynthetic pathway. 


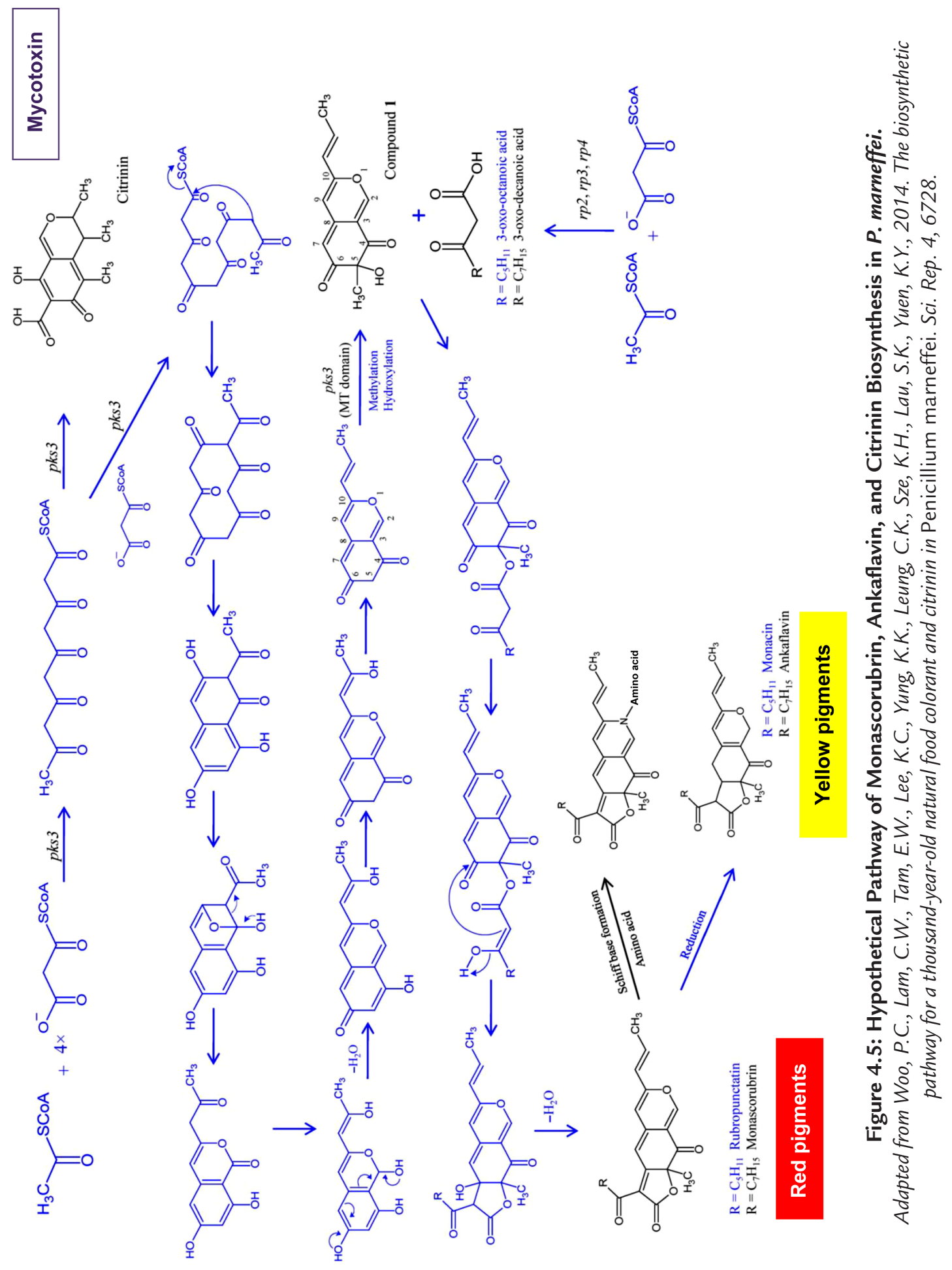




\subsection{Monascus-Like Pigments From Nontoxigenic Fungal Strains}

Some species of Talaromyces secrete large amounts of red pigments. In literature, this biosynthetic potential has been linked to species, such as Talaromyces purpurogenus, $T$. marneffei, and T. minioluteus often known under their previous Penicillium names. However, since some of them do not exert enough stability for pigment production, then such species should be avoided for scale-up production.

Isolates identified as T. purpurogenus have been reported to be of industrial interest. They can produce extracellular enzymes and red pigments, but may also produce mycotoxins, such as rubratoxin $\mathrm{A}$ and $\mathrm{B}$ and luteoskyrin in addition to extrolites that may be toxic following intraperitoneal (spiculisporic acid) and intravenal (rugulovasine A and B) injections in cats (Frisvad et al., 2004). Consequently, mycotoxin production may limit the use of isolates of a particular species in biotechnology, and Frisvad et al. (2013) concluded that T. purpurogenus may thus not be recommended for industrial production of red pigments. Talaromyces atroroseus sp. nov., described by the same group, produces the azaphilone biosynthetic families mitorubrins and Monascus pigments without being accompanied by mycotoxin synthesis (patent applications WO 2012022765, US 20,110,250,656) (Fig. 4.6). Talaromyces albobiverticillius strain isolated from Réunion Island lagoon, Indian Ocean, is also under investigation by a group of the university based on this tropical island, located between Madagascar and Mauritius. As it has been found for Monascus, these azaphilone pigments may react with amino groups containing compounds, to which reaction they owe their name, providing intense dark red colors (Gao et al., 2013; Mapari et al., 2010).
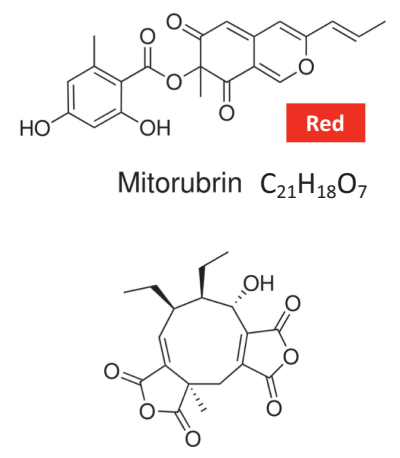

Glauconic acid $\mathrm{C}_{18} \mathrm{H}_{20} \mathrm{O}_{7}$
Colorless

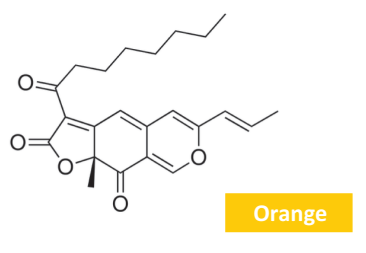

Monascorubrin $\mathrm{C}_{23} \mathrm{H}_{26} \mathrm{O}_{5}$

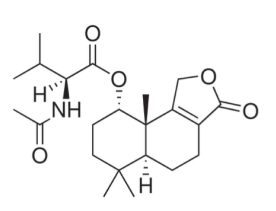

Purpuride $\mathrm{C}_{22} \mathrm{H}_{33} \mathrm{NO}_{5}$
Colorless

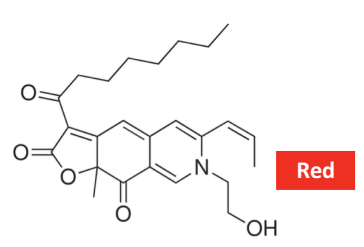

PP-R $\mathrm{C}_{25} \mathrm{H}_{32} \mathrm{NO}_{5}$

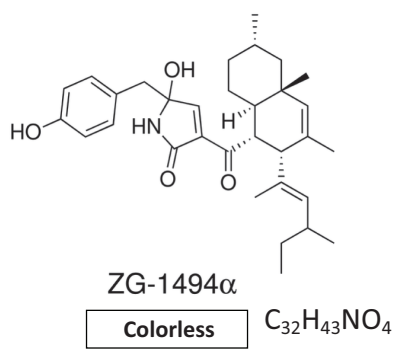

Figure 4.6: Structures of Some of the Most Characteristic Compounds Produced by Talaromyces atroroseus.

Adapted from Frisvad, J.C., Yilmaz, N., Thrane, U., Rasmussen, K.B., Houbraken, J., Samson, R.A., 2013.

Talaromyces atroroseus, a new species efficiently producing industrially relevant red pigments.

PLoS One 8 (12), e84102. 


\section{Anthraquinones}

\subsection{Fungal Natural Red}

As the first fungal commercial product claimed as a member of the anthraquinone pigment class, to which carminic acid from insect sources belongs, the natural red food colorant Arpink Red (now Natural Red) has been manufactured by two Czech companies. Ascolor Biotech s.r.o., which started the business activities followed by Natural Red produce the pigment by fermentation and bioprocess engineering using the fungal strain $P$. oxalicum var. Armeniaca CCM 8242, a soil isolate. Numerous patents have been filed by Ascolor, for example, WO 9,950,434; CZ 285,721; EP 1,070,136; US 6,340,586 cited in Sardaryan et al. (2004).

The cultivation of the fungus in liquid broth requires carbohydrates (such as sucrose, molasses), nitrogen (corn extract, yeast autolysate, or extract), zinc sulfate and magnesium sulfate. The optimum conditions for performing the microbiological synthesis are $\mathrm{pH}$ value in the range of 5.6-6.2, and temperature between 27 and $29^{\circ} \mathrm{C}$. On the second day of incubation, the red colorant is released into the broth, increasing up to $1.5-2.0 \mathrm{~g} / \mathrm{L}$ of broth after 3-4 days [WO 9,950,434; CZ 285,721; EP 1,070,136; US 6,340,586 cited in Sardaryan et al. (2004)].

After biosynthesis of the red colorant is completed, the liquid phase is filtered or centrifuged, and separated from the biomass. The liquid is then acidified to $\mathrm{pH} 3.0-2.5$ to precipitate the colorant. The precipitate is dissolved in ethyl alcohol, and filtered. Following the removal of alcohol, the crystalline form of the colorant is obtained, that is, a dark red powder.

The colorant produces a raspberry-red color in aqueous solution, stable at $\mathrm{pH}>3.5$. Neutral solutions are stable even after 30 min of boiling.

Many toxicological data are available about this red pigment. Patents contain information about acute oral toxicity in mice 90-day subchronical toxicological study, acute dermal irritation, acute eye irritation, antitumor activity, micronucleus test in mice, AMES test (Salmonella typhimurium reverse mutation assay), estimation of antibiotic activity, including results of estimation of five mycotoxins [WO 9,950,434; CZ 285,721; EP 1,070,136; US $6,340,586$ cited in Sardaryan et al. (2004)].

After evaluating all the documents provided by the company, the Codex Alimentarius Commission made the following statement on the occasion of its Rotterdam meeting on March 11-15, 2002: “... there will not be any objections to use the red colouring matter Arpink Red" in:

- meat products and meat product analogues in the amount up to $100 \mathrm{mg} / \mathrm{kg}$

- nonalcoholic drinks in the amount up to $100 \mathrm{mg} / \mathrm{kg}$

- alcoholic drinks in the amount up to $200 \mathrm{mg} / \mathrm{kg}$

- milk products and ice creams in the amount up to $150 \mathrm{mg} / \mathrm{kg}$

- confectionery in the amount up to $300 \mathrm{mg} / \mathrm{kg}$ 
Subsequently, this biotechnologically produced anthraquinone was sold and used in Czech Republic for some years. The joint FAO/WHO Expert Committee on Food Additives (JECFA) evaluation process made some progress, and the legal situation concerning Arpink Red was discussed during the 63rd Annual JECFA meeting in Geneva, June 8-17, 2004. Additional data were requested, however, the company Ascolor seemed to stop its activities, and a new company, named Natural Red, appeared in 2012.

Pros and cons are quite difficult to judge in this case, as private companies, using a fungal strain that is not publicly available, have conducted the whole development. No academic paper has been published, and much information, in particular, confirmation of genus/species of the fungal strain, chemical structure of the anthraquinone pigment(s), and absence of mycotoxins (e.g., secalonic acid D) is lacking.

\subsection{Other Fungal Anthraquinones}

Anthraquinones are widely spread in the kingdom of fungi, and thus, the latter might serve as alternative sources being independent of agroclimatic conditions in contrast to plant- and animal-derived sources. For example, anthraquinones were found in Aspergillus sp., Eurotium sp., Fusarium sp., Drechslera sp., Penicillium sp., Emericella purpurea, Curvularia lunata, Mycosphaerella rubella, Microsporum sp. (Caro et al., 2012; Gessler et al., 2013).

Anthraquinones exhibit a broad range of biological activities, including bacteriostatic, fungicidal, antiviral, herbicidal, and insecticidal effects (Gessler et al., 2013). Presumably, in fungi, these compounds are involved in interspecific interactions. For example, anthraquinones synthesized by endophytic fungi protect the host plant from insects or other microorganisms (Gessler et al., 2013).

The present picture of fungal anthraquinones is quite complex, with a great variety of chemical structures (Fig. 4.7), a huge number of factors or parameters, which may have impact on the composition of quinoidal pigments biosynthesized by a particular species. Among them, for example, habitat, light, $\mathrm{pH}$, temperature, $\mathrm{O}_{2}$ transfer, liquid/solid media, culture medium, $\mathrm{C}$ and $\mathrm{N}$ sources, $\mathrm{C}: \mathrm{N}$ ratio, presence of organic acids, mineral salts, and inoculum have been considered (Caro et al., 2012).

Today, research priority is laid on a small number of fungal anthraquinone-producing species meeting the following profile of requirements established by Mapari et al. (2009) during the identification of potentially safe fungal cell factories for the production of polyketide natural food colorants using chemotaxonomic rationale:

- fungus shall be nonpathogenic to humans,

- fungus shall be nontoxigenic under a broad range of production conditions,

- fungus shall be able to produce in liquid media. 

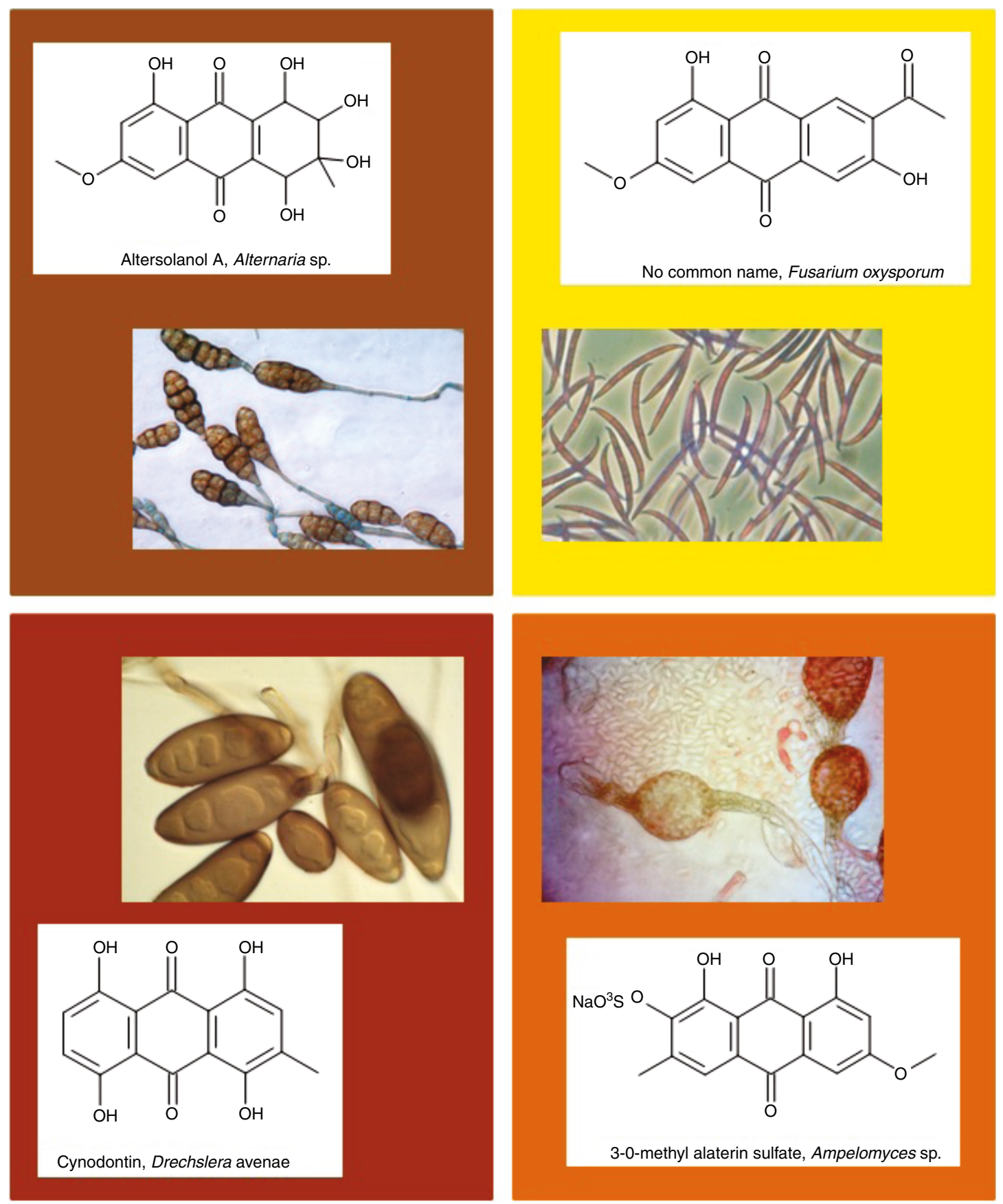

Figure 4.7: Some Anthraquinones From Fungal Origin (Color of the Box Reflects Color of the Main Pigment Produced by the Fungus). 


\section{Phycobiliproteins}

Phycobiliproteins (PBPs) belong to a group of light harvesting proteins, which are covalently bound with bilin of the tetrapyrrole prosthetic groups. PBPs are water-soluble chromoproteins present in microalgae belonging to the Rhodophyceae or Cryptophyceae and Cyanophyceae (cyanobacteria). According to their light absorption and types of bilins, PBPs are commonly divided into four subclasses: phycoerythrins (PE, pink-purple, $\lambda \max =540-570 \mathrm{~nm}$ ), phycocyanins (PC, blue, $\lambda \max =610-620 \mathrm{~nm}$ ), phycoerythrocyanins (PEC, orange, $\lambda \max =$ $560-600 \mathrm{~nm}$ ), and allophycocyanins (APC, bluish-green, $\lambda \max =650-655 \mathrm{~nm}$ ) (Kuddus et al., 2013). PBPs assemble to form supramolecular complexes called phycobilisomes contributing to light harvesting and energy transfer processes. The pigments serve as solar energy collectors in the range beyond chlorophyll $a(430 \mathrm{~nm})$ absorption. PBPs are generally formed of two chromophore-linked subunits, $\alpha$ and $\beta$, and found in trimeric $(\alpha \beta) * 3$ (MW $120 \mathrm{kDa}$ ) or hexameric units $(\alpha \beta)^{*} 6(\sim 240 \mathrm{kDa})$ (Eriksen, 2008). Some authors suggested that phycoerythrin PE may be used as a natural food colorant, by analogy to phycocyanin, exerting funny performance due to its fluorescent properties-imagine a PE-colored cocktail at night in a bar with fluorescent light! Nowadays, commercial PE is obtained from mesophile rhodophyta belonging to the genus Porphyridium. Various companies have made them available. However, the PBPs from mesophile organisms are sensitive to heat, thus displaying low stability at high temperatures. Consequently, Pumas et al. (2012) explored hot spring cyanobacteria, such as the red-violet cyanobacterium Leptolyngbya sp. producing a PE that retains up to $80 \%$ stability after being incubated at $60^{\circ} \mathrm{C}$ for $30 \mathrm{~min}$.

\section{Conclusions}

As the trend in the food and beverage markets push for more natural, organic, and clean label products, the need for more and more natural ingredients is increasing. The trend toward the formulation of recipes containing natural colors has steadily increased over recent years. Microbial and microalgal colorants are constituents of commercial products available for the food industry as a natural choice among many natural sources. They are either based on alternative production techniques of well-known pigments (e.g., $\beta$-carotene, lycopene) or specific molecules so far not biosynthesized by other organisms, such as higher plants (e.g., Monascus and Monascus-like azaphilones, aryl carotenoids) (Table 4.1).

Use of natural colors in functional, beverage, food, and crossover applications require an understanding of a variety of attributes and concepts, including heat stability, light stability, in addition to being able to provide exciting color hues. Microbial and microalgal colorants already proved to exert such properties, and novel compounds from microbial and algal biomass produced by applying biotechnological processes should render possible applicable and optimized solutions to the food and feed industry (Nupur et al., 2016; Sandmann, 2015; Zhu and Jackson, 2015). 
Table 4.1: Microbial and algal production of pigments (already in use as natural food colorants or with high potential in this field).

\begin{tabular}{|c|c|c|c|}
\hline Molecule & Color & Microorganism & Status \\
\hline Ankaflavin (azaphilone) & Yellow & $\begin{array}{l}\text { Monascus sp. (fungus) (many companies based in } \\
\text { Asia) }\end{array}$ & IP \\
\hline Anthraquinones & Red and other hues & $\begin{array}{l}\text { P. oxalicum (and many other fungi) (company } \\
\text { Natural Red, chemical structure and strain } \\
\text { should be confirmed) }\end{array}$ & IP \\
\hline Astaxanthin & Pink-red & $\begin{array}{l}\text { H. pluvialis (microalgae) (company AstaReal, } \\
\text { among many others) }\end{array}$ & IP \\
\hline Astaxanthin & Pink-red & $\begin{array}{l}\text { Xanthophyllomyces dendrorhous (yeast), formerly } \\
\text { Phaffia rhodozyma (company Ajinomoto, among } \\
\text { many others) }\end{array}$ & DS \\
\hline Astaxanthin & Pink-red & Agrobacterium aurantiacum (bacteria) & $\mathrm{RP}$ \\
\hline Astaxanthin & Pink-red & $\begin{array}{l}\text { P. carotinifaciens (bacteria) (company JX Nippon } \\
\text { Oil \& Energy) }\end{array}$ & IP \\
\hline Azaphilones & Red & $\begin{array}{l}\text { T. atroroseus (fungus) (patents from Denmark } \\
\text { Technical University, in close relationship with } \\
\text { Chr. Hansen) }\end{array}$ & DS \\
\hline Azaphilones & Red & Penicillium purpurogenum (fungus) & DS \\
\hline Azulenes & Blue & Lactarius sp. (fungus) & $\mathrm{RP}$ \\
\hline$\beta$-Carotene & Yellow-orange & $\begin{array}{l}\text { D. salina (microalgae) (company Henkel-Cognis } \\
\text { Australia) }\end{array}$ & IP \\
\hline$\beta$-Carotene & Yellow-orange & $\begin{array}{l}\text { B. trispora (fungus) (company DSM Nutritional } \\
\text { Products) }\end{array}$ & IP \\
\hline$\beta$-Carotene & Yellow-orange & Fusarium sporotrichioides (fungus) & $\mathrm{RP}$ \\
\hline$\beta$-Carotene & Yellow-orange & Mucor circinelloides (fungus) & DS \\
\hline$\beta$-Carotene & Yellow-orange & Neurospora crassa (fungus) & $\mathrm{RP}$ \\
\hline$\beta$-Carotene & Yellow-orange & Phycomyces blakesleeanus (fungus) & $\mathrm{RP}$ \\
\hline Canthaxanthin & Dark red & Bradyrhizobium sp. (bacteria) & $\mathrm{RP}$ \\
\hline Chlorophylls & Green & Many microalgae & DS \\
\hline Indigoidine & Blue & Erwinia chrysanthemi, Streptomyces lavendulae (bacteria) & $\mathrm{RP}$ \\
\hline $\begin{array}{l}\text { Isorenieratene and } \\
\text { OH derivatives (aryl } \\
\text { carotenoids) }\end{array}$ & Orange & B. linens (bacteria) & DS \\
\hline Lutein & Yellow & Chlorella and many other microalgae & IP \\
\hline Lycopene & Red & $\begin{array}{l}\text { B. trispora (fungus) (company DSM Nutritional } \\
\text { Products) }\end{array}$ & IP \\
\hline Lycopene & Red & Fusarium sporotrichioides (fungus) & RP \\
\hline Melanin & Black & Cryptococcus neoformans var. nigricans (yeast) & RP \\
\hline $\begin{array}{l}\text { Monascorubramin } \\
\text { (azaphilone) }\end{array}$ & Red & Monascus sp. (fungus) & IP \\
\hline
\end{tabular}


Table 4.1: Microbial and algal production of pigments (already in use as natural food colorants or with high potential in this field). (cont.)

\begin{tabular}{|c|c|c|c|}
\hline Molecule & Color & Microorganism & Status \\
\hline Naphtoquinone & Deep blood-red & Cordyceps unilateralis (fungus) & RP \\
\hline Phenazines & Broad range of hues & Pseudomonas and Streptomyces sp. (bacteria) & RP \\
\hline Phycocyanin & Blue & $\begin{array}{l}\text { Arthrospira sp. (formerly Spirulina sp.) and many } \\
\text { other microalgae and cyanobacteria }\end{array}$ & IP \\
\hline Phycoerythrin & Red & $\begin{array}{l}\text { Porphyridium cruentum and many other microalgae } \\
\text { and cyanobacteria }\end{array}$ & DS \\
\hline Prodigiosins & Red & Serratia marcescens (and many other bacteria) & DS \\
\hline Riboflavin & Yellow & $\begin{array}{l}\text { Ashbya gossypii (fungus), Candida famata (yeast), } \\
\text { Bacillus subtilis (bacteria) }\end{array}$ & IP \\
\hline Rubrolone & Red & Streptomyces echinoruber (bacteria) & DS \\
\hline $\begin{array}{l}\text { Rubropunctatin } \\
\text { (azaphilone) }\end{array}$ & Orange & Monascus sp. (fungus) & IP \\
\hline Torularhodin & Orange-red & Rhodotorula sp. (yeast) & DS \\
\hline Violacein & Deep violet & $\begin{array}{l}\text { Chromobacterium violaceum, Janthinobacterium lividum } \\
\text { (bacteria) }\end{array}$ & DS \\
\hline Zeaxanthin & Yellow & Flavobacterium sp. (bacteria) & DS \\
\hline Zeaxanthin & Yellow & P. zeaxanthinifaciens (bacteria) & RP \\
\hline Unknown & Red & Paecilomyces sinclairii (fungus) & RP \\
\hline
\end{tabular}

DS, Development stage; IP, industrial production; RP, research project.

\section{References}

Berman, J., Zorrilla-López, U., Farré, G., Zhu, C., Sandmann, G., Twyman, R.M., Capell, T., Christou, P., 2014. Nutritionally important carotenoids as consumer products. Phytochem. Rev. 14 (5), 727-743.

Calegari-Santos, R., Diogo, R.A., Fontana, J.D., Bonfim, T.M.B., 2016. Carotenoid production by halophilic archaea under different culture conditions. Curr. Microbiol. 72 (5), 641-651.

Caro, Y., Anamale, L., Fouillaud, M., Laurent, P., Petit, T., Dufossé, L., 2012. Natural hydroxyanthraquinoid pigments as potent food grade colorants: an overview. Nat. Prod. Bioprospect. 2, 174-193.

Castelblanco-Matiz, L.M., Barbachano-Torres, A., Ponce-Noyola, T., Ramos-Valdivia, A.C., Cerda GarcíaRojas, C.M., Flores-Ortiz, C.M., Barahona-Crisóstomo, S.K., Baeza-Cancino, M.E., Alcaíno-Gorman, J., Cifuentes-Guzmán, V.H., 2015. Carotenoid production and gene expression in an astaxanthin-overproducing Xanthophyllomyces dendrorhous mutant strain. Arch. Microbiol. 197 (10), 1129-1139.

Chang, J.-J., Thia, C., Lin, H.-Y., Liu, H.-L., Ho, F.-J., Wu, J.-T., Shih, M.-C., Li, W.-H., Huang, C.-C., 2015. Integrating an algal $\beta$-carotene hydroxylase gene into a designed carotenoid-biosynthesis pathway increases carotenoid production in yeast. Bioresour. Technol. 184, 2-8.

Chen, Y., Xiao, W., Wang, Y., Liu, H., Li, X., Yuan, Y., 2016. Lycopene overproduction in Saccharomyces cerevisiae through combining pathway engineering with host engineering. Microb. Cell Fact. 15 (1), 113.

Chi, S., He, Y., Ren, J., Su, Q., Liu, X., Chen, Z., Wang, M., Li, Y., Li, J., 2015. Overexpression of a bifunctional enzyme, CrtS, enhances astaxanthin synthesis through two pathways in Phaffia rhodozyma. Microb. Cell Fact. 14 (1), 90.

Dufossé, L., 2006. Microbial production of food grade pigments. Food Technol. Biotechnol. 44, 313-321.

Dufossé, L., 2009. Pigments, microbial. In: Schaechter, M. (Ed.), Encyclopedia of Microbiology. third ed. Elsevier/Academic Press, New York, NY, pp. 457-471. 
Dufossé, L., de Echanove, C., 2005. The last step in the biosynthesis of aryl carotenoids in the cheese ripening bacteria Brevibacterium linens ATCC 9175 (Brevibacterium aurantiacum sp. nov.) involves a cytochrome P450-dependent monooxygenase. Food Res. Int. 38, 967-973.

Dufossé, L., Fouillaud, M., Caro, Y., Mapari, S.A.S., Sutthiwong, N., 2014. Filamentous fungi are large-scale producers of pigments and colorants for the food industry. Curr. Opin. Biotechnol. 26, 56-61.

Dufossé, L., Galaup, P., Yaron, A., Arad, S.M., Blanc, P., Chidambara Murthy, K.N., Ravishankar, G.A., 2005. Microorganisms and microalgae as sources of pigments for food use: a scientific oddity or an industrial reality? Trend. Food Sci. Technol. 16, 389-406.

Eriksen, N.T., 2008. Production of phycocyanin: a pigment with applications in biology, biotechnology, foods and medicine. Appl. Microbiol. Biotechnol. 80, 1-14.

Frisvad, J.C., Smedsgaard, J., Larsen, T.O., Samson, R.A., 2004. Mycotoxins, drugs and other extrolites produced by species in Penicillium subgenus Penicillium. Stud. Mycol. 49, 201-241.

Frisvad, J.C., Yilmaz, N., Thrane, U., Rasmussen, K.B., Houbraken, J., Samson, R.A., 2013. Talaromyces atroroseus, a new species efficiently producing industrially relevant red pigments. PLoS One 8 (12), e84102.

Fu, G., Xu, Y., Li, Y., Tan, W., 2007. Construction of a replacement vector to disrupt pksCT gene for the mycotoxin citrinin biosynthesis in Monascus aurantiacus and maintain food red pigment production. Asia Pac. J. Clin. Nutr. 16 (Suppl. 1), 137-142.

Gao, J.M., Yang, S.X., Qin, J.C., 2013. Azaphilones: chemistry and biology. Chem. Rev. 113, 4755-4811.

Gessler, N.N., Egorova, A.S., Belozerskaya, T.A., 2013. Fungal anthraquinones. Appl. Biochem. Microbiol. 49, 85-99.

Grassi, T.L.M., do Espírito Santo, E.F., de Siqueira Marcos, M.T., Cavazzana, J.F., Oliveira, D.L., Bossolani, I.L.C., Ponsano, E.H.G., 2016. Bacterial pigment for Nile tilapia feeding. Aquac. Int. 24 (2), 647-660.

Guedes, A.C., Amaro, H.M., Malcata, F.X., 2011. Microalgae as sources of carotenoids. Mar. Drugs 9, $625-644$.

Guyomarc'h, F., Binet, A., Dufossé, L., 2000. Production of carotenoids by Brevibacterium linens: variation among strains, kinetic aspects and HPLC profiles. J. Ind. Microbiol. Biotechnol. 24, 64-70.

Heider, S.A.E., Peters-Wendisch, P., Netzer, R., Stafnes, M., Brautaset, T., Wendisch, V.F., 2014a. Production and glucosylation of C50 and C40 carotenoids by metabolically engineered Corynebacterium glutamicum. Appl. Microbiol. Biotechnol. 98 (3), 1223-1235.

Heider, S.A., Peters-Wendisch, P., Wendisch, V.F., Beekwilder, J., Brautaset, T., 2014b. Metabolic engineering for the microbial production of carotenoids and related products with a focus on the rare C50 carotenoids. Appl. Microbiol. Biotechnol. 98, 4355-4368.

Jaswir, I., Noviendri, D., Hasrini, R.F., Octavianti, F., 2011. Carotenoids: sources, medicinal properties and their application in food and nutraceutical industry. J. Med. Plant Res. 5 (33), 7119-7131.

Jin, W., Xu, X., Jiang, L., Zhang, Z., Li, S., Huang, H., 2015. Putative carotenoid genes expressed under the regulation of Shine-Dalgarno regions in Escherichia coli for efficient lycopene production. Biotechnol. Lett. 37 (11), 2303-2310.

Kim, S.H., Kim, M.S., Lee, B.Y., Lee, P.C., 2016. Generation of structurally novel short carotenoids and study of their biological activity. Sci. Rep. 6, 21987.

Kuddus, M., Singh, P., Thomas, G., Al-Hazimi, A., 2013. Recent developments in production and biotechnological applications of C-phycocyanin. Biomed Res. Int. 2013, 742859.

Kumar, M., Dwivedi, P., Sharma, A.K., Sankar, M., Patil, R.D., Singh, N.D., 2014. Apoptosis and lipid peroxidation in ochratoxin A- and citrinin-induced nephrotoxicity in rabbits. Toxicol. Ind. Health 30, 90-98.

Lange, B.M., Rujan, T., Martin, W., Croteau, R., 2000. Isoprenoid biosynthesis: the evolution of two ancient and distinct pathways across genomes. Proc. Natl. Acad. Sci. USA 97, 13172-13177.

Li, X.-R., Tian, G.-Q., Shen, H.-J., Liu, J.-Z., 2015. Metabolic engineering of Escherichia coli to produce zeaxanthin. J. Ind. Microbiol. Biotechnol. 42 (4), 627-636.

Lin, J.-H., Lee, D.-J., Chang, J.S., 2014. Lutein production from biomass: marigold flowers versus microalgae. Bioresour. Technol. 184, 421-428.

Mannazzu, I., Landolfo, S., da Silva, T.L., Buzzini, P., 2015. Red yeasts and carotenoid production: outlining a future for non-conventional yeasts of biotechnological interest. World J. Microbiol. Biotechnol. 31 (11), $1665-1673$ 
Mapari, S.A.S., Meyer, A.S., Thrane, U., Frisvad, J.C., 2009. Identification of potentially safe promising fungal cell factories for the production of polyketide natural food colorants using chemotaxonomic rationale. Microb. Cell Fact. 8, 24.

Mapari, S.A., Thrane, U., Meyer, A.S., 2010. Fungal polyketide azaphilone pigments as future natural food colorants? Trends Biotechnol. 28, 300-307.

Martin, H.D., Kock, S., Scherrers, R., Lutter, K., Wagener, T., Hundsdörfer, C., Frixel, S., Schaper, K., Ernst, H., Schrader, W., Görner, H., Stahl, W., 2009. 3,3'-Dihydroxyisorenieratene, a natural carotenoid with superior antioxidant and photoprotective properties. Angew. Chem. Int. Ed. 48, 400-403.

Nupur, L.N.U., Vats, A., Dhanda, S.K., Raghava, G.P.S., Pinnaka, A.K., Kumar, A., 2016. ProCarDB: a database of bacterial carotenoids. BMC Microbiol. 16 (1), 96.

Pumas, C., Peerapornpisal, Y., Vacharapiyasophon, P., Leelapornpisid, P., Boonchum, W., Ishii, M., Khanongnuch, C., 2012. Purification and characterization of a thermostable phycoerythrin from hot spring cyanobacterium Leptolyngbya sp. KC45. Int. J. Agric. Biol. 14, 121-125.

Raguenes, G., Moppert, X., Richert, L., Ratiskol, J., Payri, C., Costa, B., Guezennec, J., 2004. A novel exopolymer-producing bacterium, Paracoccus zeaxanthinifaciens subsp payriae, isolated from a "kopara" mat located in Rangiroa, an atoll of French Polynesia. Curr. Microbiol. 49, 145-151.

Sandmann, G., 2015. Carotenoids of biotechnological importance. Adv. Biochem. Eng. Biotechnol. 148, $449-467$.

Sardaryan, E., Zihlova, H., Strnad, R., Cermakova, Z., 2004. Arpink Red-meet a new natural red food colorant of microbial origin. In: Dufossé, L. (Ed.), Pigments in Food, More Than Colours.... Université de Bretagne Occidentale Publ., Quimper, France, pp. 207-208.

Schmidt-Dannert, C., Umeno, D., Arnold, F.H., 2000. Molecular breeding of carotenoid biosynthetic pathways. Nat. Biotechnol. 18, 750-753.

Silva, T.P., Paixão, S.M., Alves, L., 2016. Ability of Gordonia alkanivorans strain 1B for high added value carotenoids production. RSC Adv. 6 (63), 58055-58063.

Song, G.H., Kim, S.H., Choi, B.H., Han, S.J., Lee, P.C., 2013. Heterologous carotenoid-biosynthetic enzymes: functional complementation and effects on carotenoid profiles in Escherichia coli. Appl. Environ. Microbiol. 79, 610-618.

Takemura, M., Maoka, T., Osawa, A., Higashinaka, H., Shimada, H., Shindo, K., Misawa, N., 2015. (6E) and (6Z)$9^{\prime}$-aporhodoxanthinone, novel carotenoids produced in zeaxanthin-synthesizing-Escherichia coli by redox stress. Tetrahedron Lett. 56 (44), 6063-6065.

Thawornwiriyanun, P., Tanasupawat, S., Dechsakulwatana, C., Techkarnjanaruk, S., Suntornsuk, W., 2012. Identification of newly zeaxanthin-producing bacteria isolated from sponges in the Gulf of Thailand and their zeaxanthin production. Appl. Biochem. Biotechnol. 167, 2357-2368.

Valla, A., Cartier, D., Valla, B., Le Guillou, R., Andriamialisoa, Z., Labia, R., Breithaupt, D.E., Savy, S., Binet, A., Dufossé, L., 2003. New syntheses of natural carotene isorenieratene ( $\phi, \phi$-carotene) and its 3,3'-dimethoxy analog. Helvet. Chim. Acta 86, 3314-3319.

Wagener, S., Völker, T., De Spirt, S., Ernst, H., Stahl, W., 2012. 3,3'-Dihydroxyisorenieratene and isorenieratene prevent UV-induced DNA damage in human skin fibroblasts. Free Rad. Biol. Med. 53, 457-463.

Wang, F., Jiang, J.G., Chen, Q., 2007. Progress on molecular breeding and metabolic engineering of biosynthesis pathways of C-30, C-35, C-40, C-45, C-50 carotenoids. Biotechnol. Adv. 25, 211-222.

Woo, P.C., Lam, C.W., Tam, E.W., Lee, K.C., Yung, K.K., Leung, C.K., Sze, K.H., Lau, S.K., Yuen, K.Y., 2014. The biosynthetic pathway for a thousand-year-old natural food colorant and citrinin in Penicillium marneffei. Sci. Rep. 4, 6728.

Yang, Y., Liu, B., Du, X., Li, P., Liang, B., Cheng, X., Du, L., Huang, D., Wang, L., Wang, S., 2015. Complete genome sequence and transcriptomics analyses reveal pigment biosynthesis and regulatory mechanisms in an industrial strain, Monascus purpureus YY-1. Sci. Rep. 5, 8331.

Zhang, J.H., Lu, L.L., Yin, L.J., Xie, S., Xiao, M., 2012. Carotenogenesis gene cluster and phytoene desaturase catalyzing both three- and four-step desaturations from Rhodobacter azotoformans. FEMS Microbiol. Lett. 333, 138-145.

Zhou, P., Ye, L., Xie, W., Lv, X., Yu, H., 2015. Highly efficient biosynthesis of astaxanthin in Saccharomyces cerevisiae by integration and tuning of algal crtZ and bkt. Appl. Microbiol. Biotechnol. 99 (20), 8419-8428.

Zhu, Q., Jackson, E.N., 2015. Metabolic engineering of Yarrowia lipolytica for industrial applications. Curr. Opin. Biotechnol. 36, 65-72. 


\begin{abstract}
Pigments that produce microorganisms and microalgae are quite common in nature. However, there is a long way from the Petri dish to the market place. Ten years ago, scientists wondered if such productions would be scientific oddity or industrial reality. The answer is dual, as processes using fungi, bacteria, or microalgae already provide carotenoids or phycocyanin at an industrial level. Another production is peculiar as Monascus red-color food is consumed by more than 1 billion Asian people; however, it is still banned in many other countries. European and American consumers will follow as soon as toxin-free strains have been developed. For other pigmented biomolecules, some laboratories and companies invest a lot of money as any combination of a new source and/or new pigment requires a lot of experimental work, process optimization, toxicological studies, and regulatory approval. Time will tell whether investments in pigments, such as azaphilones or anthraquinones, were justified. Future trends involve combinatorial engineering, gene knockout, and the production of niche pigments not found in plants, such as C50 carotenoids (Furubayashi, M., Ikezumi, M., Takaichi, S., Maoka, T., Hemmi, H., Ogawa, T., Saito, K., Tobias, A.V., Umeno, D., 2015. A highly selective biosynthetic pathway to non-natural C50 carotenoids assembled from moderately selective enzymes. Nat. Commun. 6, 7534; Heider et al., 2014) or aryl carotenoids.
\end{abstract}

